\title{
Recombinant IL-7/HGF $\beta$ efficiently induces transplantable murine hematopoietic stem cells
}

\author{
Laijun Lai, ${ }^{1,2,3}$ Mingfeng Zhang, ${ }^{3}$ and Irving Goldschneider ${ }^{1}$ \\ 1Department of Immunology and 2University of Connecticut Stem Cell Institute, School of Medicine, University of Connecticut Health Center, \\ Farmington, Connecticut, USA. ${ }^{3}$ Department of Allied Health Sciences, University of Connecticut, Storrs, Connecticut, USA.
}

\begin{abstract}
Difficulty obtaining sufficient hematopoietic stem cells (HSCs) directly from the donor has limited the clinical use of HSC transplantation. Numerous attempts to stimulate the ex vivo growth of purified HSCs with cytokines and growth factors generally have induced only modest increases in HSC numbers while decreasing their in vivo reconstituting ability. We previously developed a recombinant single-chain form of a naturally occurring murine hybrid cytokine of IL-7 and the $\beta$ chain of hepatocyte growth factor (rIL-7/HGF $\beta$ ) that stimulates the in vitro proliferation and/or differentiation of common lymphoid progenitors, pre-pro-B cells, and hematopoietic progenitor cells (day 12 spleen colony-forming units) in cultures of mouse BM. Here we used the rIL-7/HGF $\beta$ in culture to induce large numbers of HSCs from multiple cell sources, including unseparated BM cells, purified HSCs, CD45- BM cells, and embryonic stem cells. In each instance, most of the HSCs were in the $\mathrm{G}_{0}$ phase of the cell cycle and exhibited reduced oxidative stress, decreased apoptosis, and increased CXCR4 expression. Furthermore, when injected i.v., these HSCs migrated to BM, self-replicated, provided radioprotection, and established long-term hematopoietic reconstitution. These properties were amplified by injection of rIL-7/HGF $\beta$ directly into the BM cavity but not by treatment with rIL-7, rHGF, and/or rHGF $\beta$.
\end{abstract}

\section{Introduction}

An elusive goal in BM reconstitution therapy has been the establishment of conditions under which large numbers of transplantable hematopoietic stem cells (HSCs) can be selectively generated in vitro (1-4). Two major approaches using purified HSCs have been taken. In the first, gene transfer techniques featuring the overexpression of NOTCH-1, WNT, or HOXB4 were used to influence the survival and proliferation of HSCs in vitro (5-7). Although successful in several instances, this strategy has raised safety concerns that thus far have prohibited its clinical use.

In the second approach, a number of growth factors and soluble proteins were used to expand HSCs in vitro. Of the numerous cytokines that have been tested, none has thus far been able to stimulate the generation of sufficient functional HSCs for clinical application. This negative effect has been attributed to the decline or loss of long-term in vivo repopulating abilities $(4,5,8)$ secondary to the entrance of HSCs into cell cycle (9-11). Therefore, only cytokines that maintain HSCs in $\mathrm{G}_{0}$ phase, such as SDF-1, TGF- $\beta$, FGF, and angiopoietin- 1 , have been found to preserve their engraftment ability (12-15).

Unfortunately, even these factors, whether used alone or in combination, were unable to stimulate sufficient HSC formation. Notably, the retroviral transduction of 5-FU-treated BM cells with the receptor for FGF-1 has shown promise (16). However, as FGF-1 has been shown to act indirectly by inducing other cells to stimulate HSCs, it is not known whether such an approach would be successful in cultures of purified HSCs.

Conflict of interest: Laijun Lai and Irving Goldschneider hold US patent No. 6,749,847 ("Hybrid Cytokine of IL-7 and $\beta$-chain of Hepatocyte Growth Factor") and US patent No. 7,578,998 ("Chimeric Cytokine of IL-7 and $\beta$-chain of HGF and Methods of Use").

Citation for this article: J Clin Invest. 2012;122(10):3552-3562. doi:10.1172/JCI46055.
Another approach to generating HSCs in vitro has used embryonic stem cells (ESCs), which are less prone than HSCs to replicative senescence and differentiation in vitro. However, the HSCs that have been produced by ESCs in stromal cell-dependent cultures lacked the ability to reconstitute the hematopoietic system efficiently when infused in vivo, possibly because they were not adult-type (definitive) HSCs (17).

We have demonstrated that a recombinant single-chain form of a naturally occurring, BM stromal cell-derived, hybrid cytokine consisting of murine IL- 7 and the $\beta$ chain of the hepatocyte growth factor (rIL-7/HGF $\beta$ ) stimulates the expansion of day 12 spleen colonyforming units (CFU-S ${ }_{12}$ ), common lymphoid progenitors (CLPs), pre-pro-B cells, and thymocytes in vitro (18) and greatly enhances the thymopoiesis and naive $\mathrm{T}$ cell regeneration after BM transplantation in vivo (19). In this study, we show that rIL-7/HGF $\beta$, but not its component cytokines, also stimulated the generation of large numbers of definitive HSCs in long-term cultures of adult BM cells. The results indicated that rIL-7/HGF $\beta$ maintains the hematopoietic reconstituting potential of these HSCs by inhibiting their proliferation, reducing oxidative stress and apoptosis, and increasing CXCR4 expression. Moreover, the fact that almost all of the culture-generated HSCs were in $\mathrm{G}_{0}$ phase raised the possibility that they had been generated by earlier precursors. This was confirmed by demonstrating that rIL-7/HGF $\beta$ induced the rapid generation of HSCs in short-term cultures of purified CD $45^{-} \mathrm{Lin}^{-} \mathrm{Sca}-1^{+} \mathrm{BM}$ cells, which have been reported to contain the most primitive cells in adult BM, including some that could serve (albeit inefficiently) as the precursors of HSCs in vivo (20-24). Furthermore, we demonstrated that rIL-7/HGF $\beta$-responsive precursors of HSCs resided within the SSEA ${ }^{+} \mathrm{IL}-7 \mathrm{R}^{+} \mathrm{c}-\mathrm{Met}^{+}$subset of the CD45-Lin ${ }^{-} \mathrm{BM}$ cells.

In addition to stimulating the generation of HSCs from CD45 precursors, rIL-7/HGF $\beta$ was able to prevent proliferating HSCs from losing their in vivo repopulating abilities. This permitted 


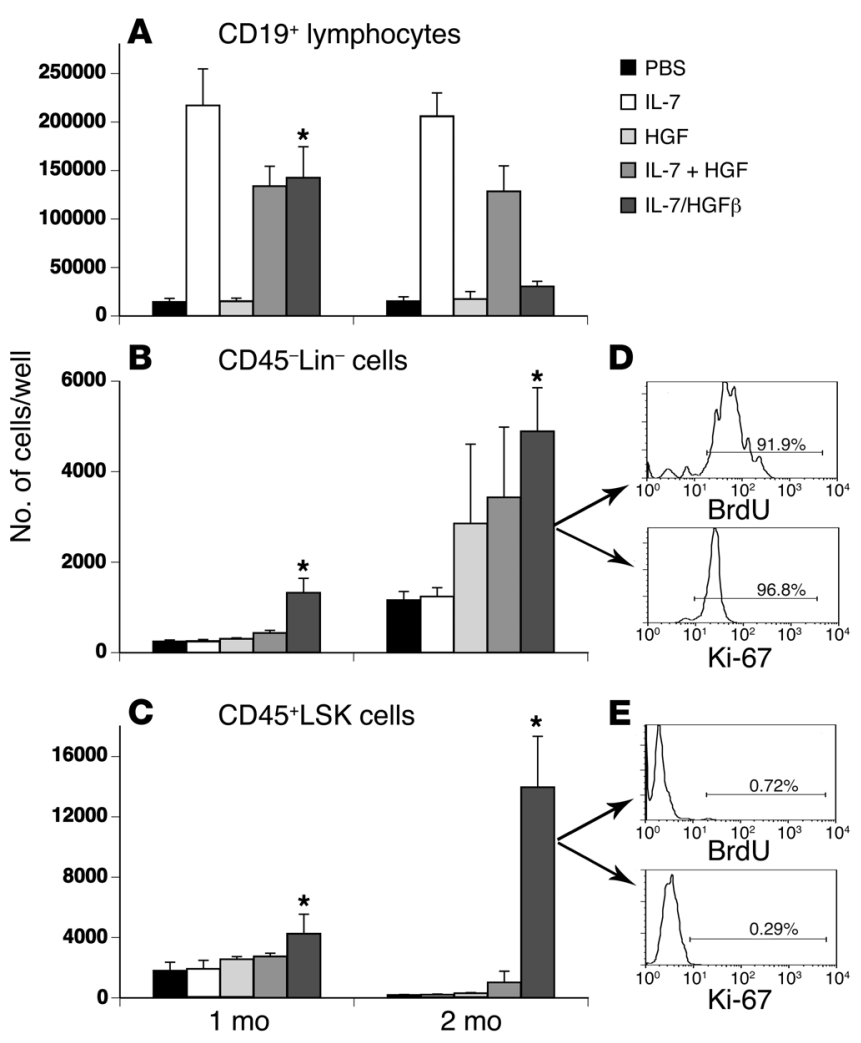

large numbers of transplantable HSCs to be produced in rSCFand rFlt3L-stimulated short-term cultures of unfractionated BM cells or purified HSCs. rIL-7/HGF $\beta$ was also able to induce murine ESCs to selectively form HSCs in OP-9 stromal cell cocultures, apparently through a CD45-Lin- ${ }^{-} \mathrm{SSEA}^{+} \mathrm{IL}-7 \mathrm{R} \alpha^{+} \mathrm{c}-\mathrm{Met}^{+}$intermediate. In all of these systems, the culture-generated HSCs competitively established prolonged, multilineage hematopoietic cell chimerism in vivo. However, the ESC-derived HSCs required the injection of IL-7/HGF $\beta$ intrafemorally (i.f.) to establish hematopoietic chimerism, whereas this procedure helped to optimize, but was not essential for, the establishment of chimerism by the adult BM cell-derived HSCs. These in vitro and in vivo effects of the rIL-7/HGF $\beta$ fusion protein appeared to be unique, as they could not be replicated in whole or part by rIL-7, rHGF, and/or rHGF $\beta$.

\section{Results}

rIL-7/HGF $\beta$ stimulates the in vitro production of $\mathrm{CD} 45^{+} \mathrm{Lin}^{-} \mathrm{Sca}-1^{+} \mathrm{C}-\mathrm{Kit}^{+}$ cells in long-term BM cell cultures. As we reported (18), mouse BM cells cultured in vitro for 3 to 4 weeks in the presence of rIL-7/

\section{Figure 2}

In vivo hematopoietic repopulating potential of cells from long-term rIL-7/ HGF $\beta$-containing BM cultures. $3 \times 10^{4}$ cells from 2-month cultures of rlL-7/ HGF $\beta$, rlL-7, and/or rHGF-stimulated BM cells were mixed with $2 \times 10^{5}$ freshly harvested WT BM cells and injected i.v. into lethally irradiated WT recipients. Twelve weeks later, the percentages of donor-origin $\left(G^{2} P^{+}\right)$cells in the blood of mice that had received cells from cultures containing (A) rIL-7, (B) rHGF, (C) rlL-7 plus rHGF, or (D) rlL-7/HGF $\beta$ were determined. The presence of $(E) T$ cells $\left(\mathrm{CD}^{+}\right)$and $B$ cells $\left(\mathrm{CD} 19^{+}\right)$and $(\mathrm{F})$ myeloid cells $\left(\mathrm{Gr}-1^{-} \mathrm{CD} 11 \mathrm{~b}^{+}\right)$and granulocytes $\left(\mathrm{Gr}-1^{+}\right)$ as well as $(\mathbf{G})$ the numbers of these cells among the donor-origin cells is shown. One representative experiment out of 3 is shown.

\section{Figure 1}

rIL-7/HGF $\beta$ induces the appearance of CD45+LSK cells in long-term BM cultures. Normal adult mouse BM cells were cultured in the presence of $\mathrm{rlL}-7 / \mathrm{HGF} \beta(30 \mathrm{ng} / \mathrm{ml})$, rlL-7 $(10 \mathrm{ng} / \mathrm{ml})$, and/or $\mathrm{rHGF}(25 \mathrm{ng} / \mathrm{ml})$, and the total numbers of (A) CD19+ B cells, (B) CD45-Lin- cells, and (C) CD45+LSK cells were determined at 1 and 2 months. Results represent the mean \pm SD of the total cells of each type derived from $1 \times 10^{6} \mathrm{BM}$ cells. ${ }^{*} P<0.05$ as compared with PBS control. In addition, the percentages of the (D) CD45-Lin- and (E) CD45+LSK cells that incorporated BrdU (45-minute pulse) and expressed Ki-67 were determined for the 2 month rIL-7/HGF $\beta$-containing cultures. One representative experiment out of 3 is shown.

HGF $\beta$ generated large numbers of CFU-S ${ }_{12}$, CLPs, pre-pro-B cells, and pro-B cells in vitro (data not shown). However, as shown in Figure 1, A-C, when the culture period was extended to 2 months, the number of CD $19^{+}$B-lineage cells decreased markedly and the numbers of CD45-Lin- (presumptive nonhematopoietic) cells and $\mathrm{CD} 45^{+} \mathrm{Lin}^{-} \mathrm{Sca}-1^{+} \mathrm{C}-\mathrm{Kit}^{+}\left(\mathrm{CD} 45^{+} \mathrm{LSK}\right)$ (presumptive hematopoietic stem and progenitor) cells increased markedly $(5,000$ and 14,000 cells/well, respectively), exceeding those in the original BM cell inoculum by 15 - to 20 -fold. More than $90 \%$ of the CD45-Lin- cells incorporated BrdU within 45 minutes, and less than $2 \%$ were in $\mathrm{G}_{0}$ phase when stained with Ki-67 (Figure 1D). In contrast, less than $1 \%$ of the CD $45^{+}$LSK cells (approximately $65 \%$ having the Flt $3^{-}$phenotype of HSCs and $35 \%$ having the Flt $3^{+}$phenotype of multipotent progenitors [MPPs]) incorporated $\mathrm{BrdU}$ and were in $\mathrm{G}_{0}$ phase (Figure $1 \mathrm{E}$ ). These results raised the possibility that most of the HSCs in these cultures had been generated by rapidly proliferating precursors, possibly among the CD45- Lin $^{-}$cell population, and that the MPPs had differentiated from these HSCs, possibly without proliferation. Furthermore,
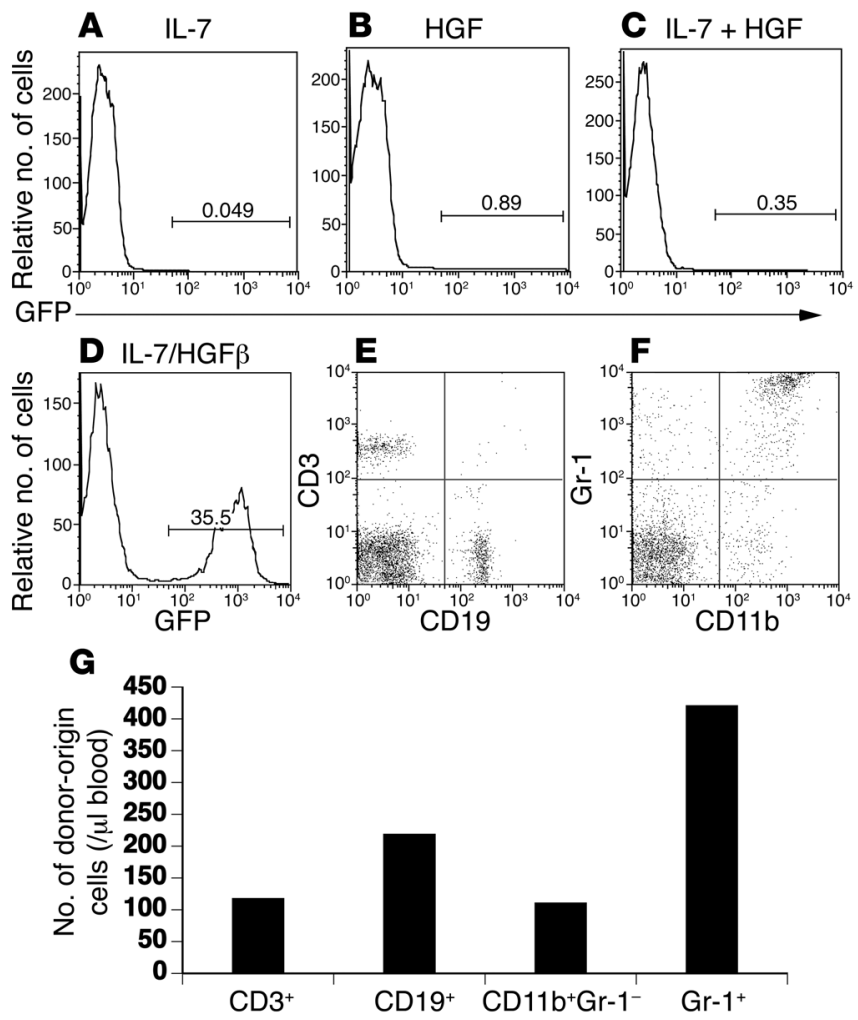
Table 1

Hematopoietic chimerism in various tissues of primary recipients of culture-generated BM cells

\begin{tabular}{lcccc}
\hline & & & & \\
\% of total donor-origin cells & BM & BL & SP & LN \\
T cells & $2.1 \pm 2.0$ & $15.9 \pm 13.4$ & $17.0 \pm 0.2$ & $67.0 \pm 0.7$ \\
& $(0.7 \pm 0.5)$ & $(18.5 \pm 9.0)$ & $(22.9 \pm 2.8)$ & $(69.6 \pm 2.2)$ \\
B cells & $26.2 \pm 9.3$ & $29.5 \pm 5.9$ & $25.2 \pm 1.4^{A}$ & $30.2 \pm 2.1$ \\
& $(26.7 \pm 2.3)$ & $(26.3 \pm 9.1)$ & $(42.8 \pm 2.4)$ & $(32.8 \pm 2.4)$ \\
Myeloid cells & $14.6 \pm 0.4$ & $12.0 \pm 3.5$ & $6.3 \pm 0.4$ & $3.3 \pm 0.8$ \\
& $(9.4 \pm 1.0)$ & $(11.8 \pm 1.9)$ & $(7.6 \pm 0.3)$ & $(3.6 \pm 2.0)$ \\
Granulocytes & $42.4 \pm 2.6$ & $52.1 \pm 6.7$ & $37.3 \pm 4.5^{A}$ & $1.9 \pm 0.6$ \\
& $(37.8 \pm 6.7)$ & $(50.5 \pm 18.7)$ & $(19.8 \pm 3.5)$ & $(3.4 \pm 0.8)$
\end{tabular}

$3 \times 10^{4}$ cells from 2-month-old cultures of IL-7/HGF $\beta$-stimulated BM (GFP+) were mixed with $2 \times 10^{5}$ WT BM cells and injected i.v. into 10 Gy-irradiated WT recipients. For controls (indicated in parentheses), $2 \times 10^{5}$ freshly harvested BM cells from GFP+ mice were mixed with $2 \times 10^{5}$ WT BM cells. Twenty-one weeks later, the distribution of donor-origin (GFP+) $\mathrm{Lin}^{+}$cells in various tissues (red blood cells were lysed first) was determined by FACS analysis. Mean \pm SD of 3 recipients; one representative experiment out of 3 is shown. ${ }^{A} P \leq 0.05$ between experimental and control values. recipients resembled that in the BM from the primary recipients, with the exception of a significant increase in the proportion of HSCs (Figure 3B).

It should be noted that no Ly $5.2^{+} \mathrm{GFP}^{+}$cells were observed in any of the chimeras (data not shown), indicating that fusion between donor-origin $\left(\mathrm{Ly} 5.1^{+} \mathrm{GFP}^{+}\right)$and recipient (Ly5.2 ${ }^{+} \mathrm{GFP}^{-}$) cells did not contribute to the observed hematopoietic reconstitution $(25,26)$. Importantly, no tumor formation was seen in any of the recipients observed for up to 8 months.

i.f. injection of $r I L-7 / H G F \beta$ enhances the migration to $B M$ and

the effect of rIL-7/HGF $\beta$ on the generation of HSCs and MPPs in these cultures appeared to be unique, as PBS, rIL-7, and/or rHGF (or HGF $\beta$; data not shown) supported the generation of CD45-Lin', but not CD45 ${ }^{+} \mathrm{LSK}$, cells.

Cells from rIL-7/HGFß-stimulated BM cell cultures establish long-term hematopoietic chimerism in vivo. Competitive repopulating assays were conducted to determine whether the rIL-7/HGF $\beta$-stimulated $\mathrm{BM}$ cells could reconstitute the hematopoietic system of lethally irradiated mice. In these experiments, $3 \times 10^{4}$ cells from 2 -month-old cultures of rIL-7/HGF $\beta$-, rIL-7-, and/or rHGF-stimulated (or HGF $\beta$-stimulated) EGFP Tg BM cells were mixed with $2 \times 10^{5}$ freshly harvested WT BM cells and injected i.v. into $10 \mathrm{~Gy}-$ irradiated WT recipients. Twelve weeks later, the blood was analyzed for donor-origin $\left(\mathrm{GFP}^{+}\right)$nucleated cells. As shown in Figure 2, only mice that received cells from the rIL-7/HGF $\beta$-containing cultures displayed multilineage hematopoietic chimerism. In other experiments (Table 1), hematopoietic chimerism (14\%-22\% $\mathrm{GFP}^{+}$cells) was observed in a variety of tissues (e.g., BM, blood [BL], spleen [SP], LN) as late as 21 weeks after adoptive transfer of 2-month-old cultures of rIL-7/HGF $\beta$-stimulated BM cells; and the proportions of the major donor-origin leukocyte subsets generated were similar to those obtained when freshly harvested (noncultured) $\mathrm{GFP}^{+} \mathrm{BM}$ cells were used as controls. Furthermore, the donor-origin BM cells in the experimental and control recipients demonstrated equivalent hematopoietic renewal potentials 12 weeks after i.v. injection into secondary irradiated recipients (Table 2).

To demonstrate more directly that the culture-generated HSCs were self-renewing, BM cells from the primary recipients were transferred at 14 weeks into irradiated secondary recipients, and the Lin $^{-}$donor-origin $\mathrm{BM}$ cells were examined 4 weeks later. The results in Figure $3 \mathrm{~A}$ show that approximately $15 \%$ of the total $\mathrm{Lin}^{-}$cells in the BM of the secondary recipients were of donor origin. This was approximately twice that present in the BM that was transferred from the primary recipients. Furthermore, the subset distribution of the donor-origin Lin- BM cells in the secondary
Table 2

Hematopoietic chimerism in various tissues of secondary recipients of culture-generated BM cells

\begin{tabular}{lccc}
\hline & & & \\
\% of total donor-origin cells & $\mathbf{B M}$ & $\mathbf{B L}$ & $\mathbf{S P}$ \\
T cells & $5.3 \pm 2.4$ & $6.5 \pm 7.8$ & $13.4 \pm 10.7$ \\
& $(4.5 \pm 3.1)$ & $(11.5 \pm 2.4)$ & $(16.4 \pm 7.6)$ \\
B cells & $16.4 \pm 15.2$ & $43.5 \pm 16.9$ & $59.4 \pm 9.6$ \\
& $(13.4 \pm 9.5)$ & $(49.7 \pm 11.1)$ & $(58.5 \pm 13.3)$ \\
Myeloid cells & $6.0 \pm 1.7$ & $12.6 \pm 2.9$ & $7.8 \pm 2.5$ \\
& $(5.9 \pm 0.3)$ & $(12.6 \pm 3.3)$ & $(7.9 \pm 0.6)$ \\
Granulocytes & $59.4 \pm 16.6$ & $58.5 \pm 17.3$ & $16.8 \pm 11.6$ \\
& $(52.8 \pm 12.0)$ & $(49.3 \pm 10.5)$ & $(18.5 \pm 3.9)$
\end{tabular}

$1 \times 10^{6} \mathrm{BM}$ cells, including controls (indicated in parentheses), obtained from primary recipients after 14 weeks, were mixed with $1.5 \times 10^{6}$ WT BM cells and injected i.v. into 10 Gy-irradiated WT secondary recipients. Twelve weeks later, the distribution of donor-origin (GFP+) $\mathrm{Lin}^{+}$cells in various tissues was determined by FACS analysis. Mean \pm SD of 3 recipients; one representative experiment out of 2 is shown. 
A
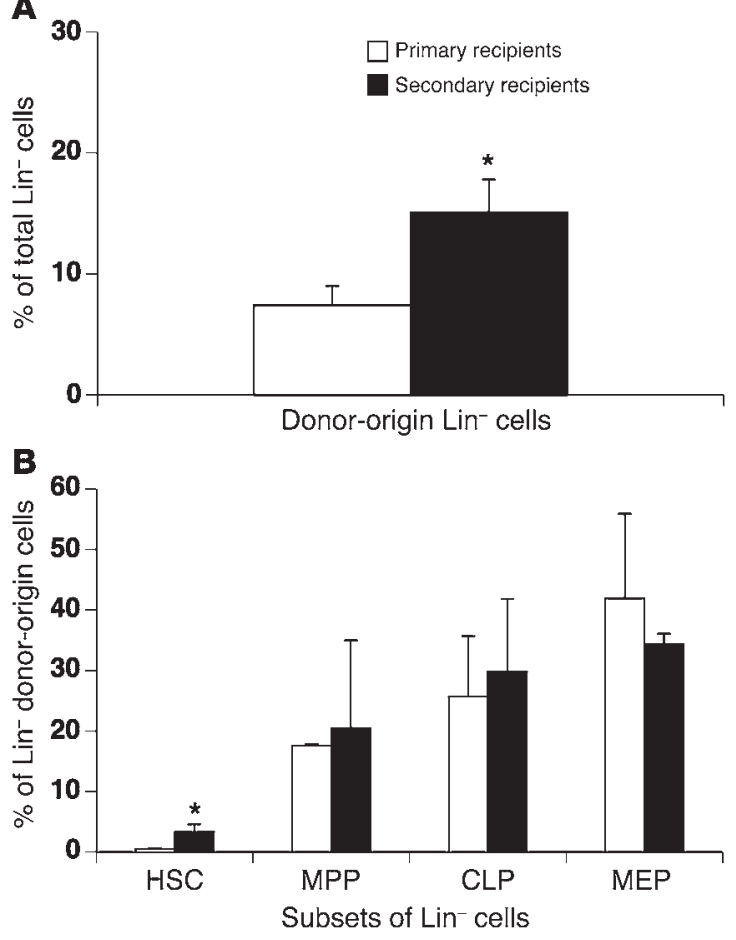

Given our prior demonstration (19) that systemically injected rIL-7/HGF $\beta$ significantly enhanced thymocytopoiesis after syngeneic BM transplantation, we determined whether i.f.-injected rIL-7/HGF $\beta$ would have a similar effect using culture-generated HSCs. As shown in Figure 4B, i.f. rIL-7/HGF $\beta$ induced a 2-fold increase in thymocyte chimerism over i.f. PBS (27\% vs. $13 \%$; $P<0.05)$. This suggested that one of the supportive effects of the systemic administration of rIL-7/HGF $\beta$ on thymopoiesis occurs at least partly in the BM (19).

Enhanced migration of hematopoietic stem and progenitor cells from the blood to the BM could be one of the mechanisms by which i.f. injection of rIL-7/HGF $\beta$ increases hematopoietic and thymopoietic chimerism. To test this, mice were injected i.f. with rIL-7/HGF $\beta$ and i.v. with cultured BM cells. As shown in Figure 5, i.f. injection of rIL-7/HGF $\beta$ significantly $(P<0.05)$ increased the number of rIL-7/HGF $\beta$ (but not rIL-7 or rHGF) culture-generated cells in the BM by 15 - to 20 -fold within 24 hours.

SCF and Flt3L accelerate the production of transplantable HSCs in short-term rIL-7/HGFß-containing BM cultures. Early-acting cytokines, such as stem cell factor (SF) and Flt3 ligand (FL), are able to stimulate the proliferation of HSCs in vitro (30). However,

\section{Figure 4}

i.f. injection of rlL-7/HGF $\beta$ enhances the establishment of hematopoietic and thymic chimerism by cells from long-term rIL-7/HGF $\beta$-containing BM cultures. GFP+ BM cells, cultured for 2 months in the presence of rIL-7/HGF $\beta$, rlL-7, and/or rHGF, were mixed with freshly harvested WT BM cells and injected i.v. into lethally irradiated WT recipients that had also been injected i.f. with rIL-7/HGF $\beta$ (500 ng) initially and at monthly intervals thereafter. (A) The levels of multilineage hematopoietic chimerism in the blood and (B) thymocyte chimerism were determined 12 weeks after cell transfer. Mean \pm SD from 4 to 6 mice per group. ${ }^{*} P<0.05$ as compared with PBS control. One representative experiment out of 3 is shown.

\section{Figure 3}

Self-renewal of HSCs in recipients of cells from long-term rlL-7/HGF $\beta$ containing BM cultures. $20 \times 10^{6}$ cells from 10 Gy-irradiated mice that had received mixtures of culture-generated and WT BM cells i.v. 14 weeks previously (primary recipients) were injected i.v. into irradiated WT mice (secondary recipients). (A) The percentage of Lin- cells of donor-origin $\left(\mathrm{GFP}^{+}\right)$and (B) their subset distribution in the BM of the secondary recipients was determined 4 weeks later. Mean \pm SD of 4 to 6 mice per group. ${ }^{*} P<0.05$ as compared with BM cells from the primary recipients. HSC, Flt3-LSK; MPP, Flt3+LSK; CLP, IL-7R $\alpha^{+}$LSK; MEP, Flt3+Sca-1-c-kit+. One representative experiment out of 2 is shown.

these HSCs lose most of their in vivo hematopoietic repopulating capacity when they enter cell cycle. We therefore determined whether rIL-7/HGF $\beta$, which does not induce the proliferation of HSCs in vitro (Figure 1E), could preserve the long-term repopulating capacity of HSCs generated in the presence of SF and FL. In these experiments, $1 \times 10^{6}$ normal BM cells or $0.5 \times 10^{3}$ to $2 \times 10^{3}$ purified HSCs (Flt3-LSK cells) therefrom were cultured for 7 to 12 days with a mixture of SF and FL (SF/FL) in the presence or absence of rIL-7/HGF $\beta$, rIL-7, and/or rHGF. Under these circumstances, all of the cultures contained elevated numbers of CD $45^{+}$LSK cells $\left(2 \times 10^{4}\right.$ to $\left.3 \times 10^{4}\right)$, suggesting that, unlike longterm rIL-7/HGF $\beta$-containing BM cell cultures, most of the HSCs in the short-term SF/FL-containing BM cell cultures were generated by the proliferation of preexisting HSCs. Yet, as shown in Figure 6, only the cells from the rIL-7/HGF $\beta$-containing cultures were able to establish long-term (22-24 weeks) hematopoietic chimerism in adoptive recipients.

At least 4 differences between the rIL-7/HGF $\beta$-containing cultures and those not containing rIL-7/HGF $\beta$ might help to explain these results. First, the LSK cells in the rIL-7/HGF $\beta$-containing cultures expressed significantly lower levels of ROS than did their counterparts in non-rIL-7/HGF $\beta$-containing cultures (Figure 7A). Second, a significantly lower proportion of the LSK cells in the
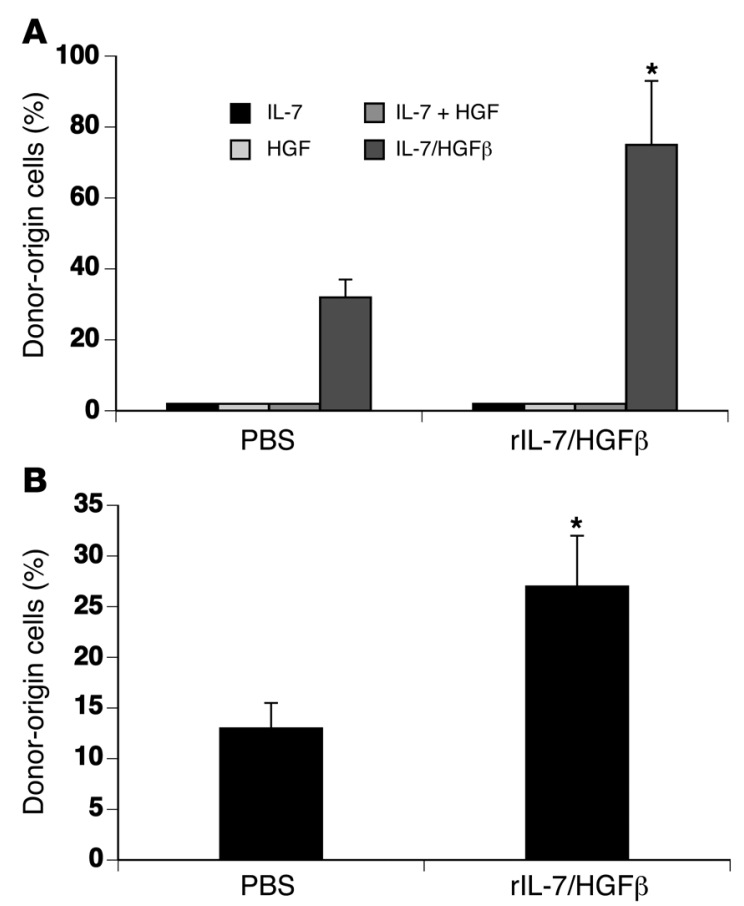


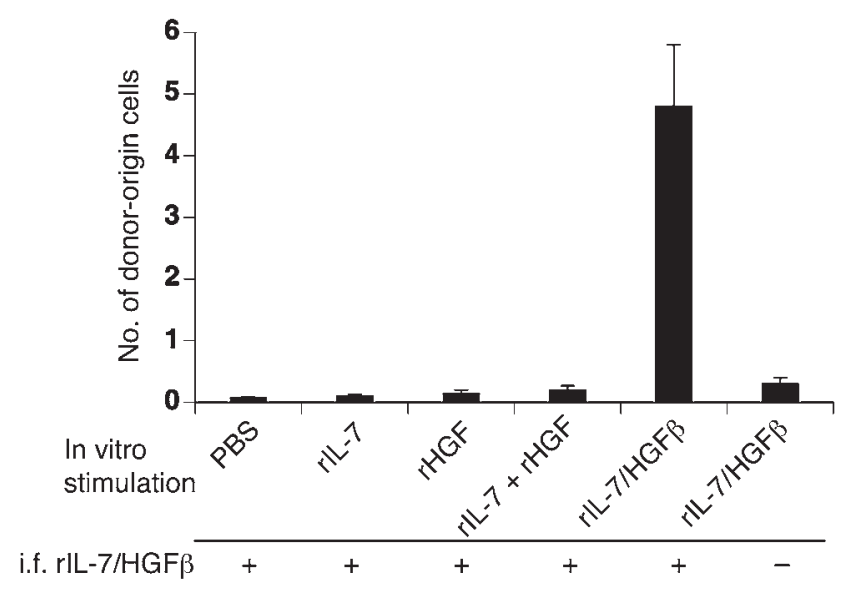

rIL-7/HGF $\beta$-containing cultures incorporated BrdU (Figure 7B). Third, a significantly lower proportion of the LSK cells in the rIL-7/ HGF $\beta$-containing cultures were annexin V-positive (Figure 7C), including propidium iodide-positive and -negative subsets. Fourth, a significantly higher proportion of the LSK cells in the rIL-7/HGF $\beta$-containing cultures expressed CXCR4 (Figure 7D). These effects were restricted to rIL-7/HGF $\beta$ and were not seen in cultures containing the individual factors rIL-7 and/or rHGF $\beta$ (data not shown). Hence, the addition of rIL-7/HGF $\beta$ to SF/FLcontaining cultures appeared to maintain the hematopoietic reconstituting potential of these proliferating HSCs, at least in part, by protecting them against oxidative stress (possibly by enabling them to revert to the quiescent state; ref. 31), enhancing their survival, and increasing their ability to home to the BM (32). rIL-7/HGF $\beta$ induces purified CD45- Lin $^{-}$Sca- $1^{+}$BM cells and the CD45- in $^{-} S S E A^{+} I L-7 R \alpha^{+}$c-Met ${ }^{+}$subset therein to generate HSCs in vitro. To test the hypothesis first suggested by the data in Figure 1 that most of the CD $45^{+}$LSK cells in long-term rIL-7/HGF $\beta$-containing $\mathrm{BM}$ cell cultures are generated by $\mathrm{CD}^{4} 5^{-}$precursors, we purified (>98\%) CD45- $\mathrm{Lin}^{-} \mathrm{Sca}-1^{+}$cells from normal BM and placed them in culture for 12 days in the presence of rIL-7/HGF $\beta$, rIL-7, and/or rHGF (or PBS). As with the long-term BM cell cultures (Figure 1C), only the rIL-7/HGF $\beta$-containing short-term cultures of purified CD45- $\mathrm{Lin}^{-} \mathrm{Sca}-1^{+} \mathrm{BM}$ cells generated CD $45^{+} \mathrm{LSK}$ cells. However, unlike the long-term BM cell cultures, CD $45^{+}$LSK cells comprised approximately $30 \%$ (as opposed to $1 \%-2 \%$ ) of the total cells in the short-term cultures of purified CD45-Lin-Sca- ${ }^{+}$BM cells (Figure 8A). Of these, approximately $75 \%$ were putative HSCs (Flt $3^{-}$) and 25\% were MPPs (Flt $3^{+}$) (data not shown). Again, only the cells from the rIL-7/HGF $\beta$-containing cultures competitively repopulated the hematopoietic system (Figure $8 \mathrm{~B}$ ) and provided radioprotection (data not shown) in vivo. In contrast, neither

\section{Figure 6}

rlL-7/HGF $\beta$ maintains the hematopoietic reconstituting activity of cells generated in short-term cultures of SF/FL-stimulated BM cells. BM was cultured with $50 \mathrm{ng} / \mathrm{ml} \mathrm{SF}$ and $\mathrm{FL}$ in the presence or absence of rlL-7/HGF $\beta$, rlL-7, and/or rHGF. The proportions of donor-origin (GFP+) hematopoietic cells in the blood of sublethally irradiated $(6 \mathrm{~Gy})$ recipients 22 to 24 weeks after the i.v. transfer of $2 \times 10^{5}$ culture-generated and $2 \times 10^{5}$ WT BM cells were determined. As indicated, some of the recipients also were injected i.f. with rIL-7/HGF $\beta$. Mean \pm SD of 4 to 6 mice per group. One representative experiment out of 2 is shown.

\section{Figure 5}

i.f. injection of rlL-7/HGF $\beta$ induces the migration of cells from long-term rIL-7/HGF $\beta$-containing BM cultures from blood to BM. Lethally irradiated WT recipients were injected i.f. with $500 \mathrm{ng}$ rIL-7/HGF $\beta$ and i.v. with GFP+ BM cells cultured for 2 months in the presence of PBS, rIL-7/HGF $\beta$, rIL-7, and/or rHGF $\left(5 \times 10^{5}\right)$. GFP+ cells in the injected femurs were analyzed 24 hours later. Mean \pm SD of groups of 3 mice. One representative experiment out of 3 is shown.

hematopoiesis nor radioprotection occurred when freshly purified CD45- Lin $^{-} \mathrm{Sca}-1^{+} \mathrm{BM}$ cells themselves were placed directly in vivo (Figure 8B and data not shown).

Consistent with published results (20), approximately $75 \%$ of the purified CD45- $\mathrm{Lin}^{-} \mathrm{Sca}-1^{+} \mathrm{BM}$ cells were $\mathrm{SSEA}^{+}$(data not shown), indicating that they were developmentally less mature than HSCs. In addition (and also unlike HSCs), approximately 30\% of the $\mathrm{SSEA}^{+}$cells expressed the IL-7R $\alpha$ chain as well as c-Met, the receptor for HGF. Inasmuch as rIL-7/HGF $\beta$ acts selectively on dual receptor-expressing cells (ref. 18 and our unpublished observations), we hypothesized that, at a minimum, the SSEA ${ }^{+} \mathrm{IL}-7 \mathrm{R} \alpha^{+} \mathrm{c}-\mathrm{Met}^{+}$ subset of CD45- $\mathrm{Lin}^{-} \mathrm{BM}$ cells contained the immediate precursors of the HSCs that are formed in these cultures. To test this, purified CD45-Lin-SSEA ${ }^{+}$IL-7R $\alpha^{+} \mathrm{c}-\mathrm{Met}^{+} \mathrm{BM}$ cells were cultured for 12 days with rIL-7/HGF $\beta$ (or PBS). As shown in Figure 9A, these cultures generated HSCs, MPPs, megakaryocytic erythroid progenitors (MEPs), and CLPs in vitro. In addition, these cells competitively repopulated the hematopoietic system after i.v. injection into primary (Figure 9B) and secondary (Figure 9C) recipients. In contrast, CD45- Lin $^{-} \mathrm{Sca}-{ }^{+}{ }^{+}$SSEA ${ }^{+}$BM cells that failed to express IL-7R $\alpha$ and c-Met did not generate HSCs, MPPs, MEPs, and CLPs in the presence of rIL-7/HGF $\beta$ (data not shown).

$r I L-7 / H G F \beta$ enhances the generation of HSCs by ESCs in vitro. To further demonstrate that $\mathrm{rIL}-7 / \mathrm{HGF} \beta$ can induce primitive precursors to generate HSCs in vitro, we cocultured undifferentiated murine ESCs (TC-1/EGFP) with OP9 cells for 12 days in the presence of equimolar amounts of rIL-7/HGF $\beta$, rIL-7, and/or rHGF (or PBS). The cells from these cultures were then injected i.v. $\left(2 \times 10^{6}\right)$ into sublethally irradiated (6 Gy) 129SVEV Tac mice. As shown in Figures 10 and 11, only the cells from the rIL-7/HGF $\beta$-containing ESC cocultures were able to reconstitute the hematopoietic system after i.v. injection. However, unlike the HSCs generated in cultures of purified CD $45-\mathrm{Lin}^{-} \mathrm{Sca}-1^{+}$cells from adult BM (Figure 8), the ESC-derived HSCs required the i.f. injection of rIL-7/HGF $\beta$ to establish chimerism. Again, the i.f. injection of rIL-7/HGF $\beta$ (or rIL-7 and/or

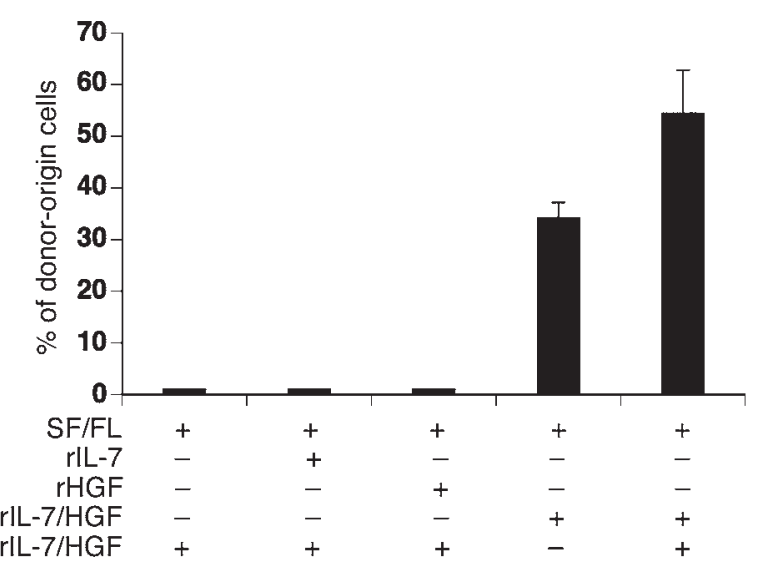


A

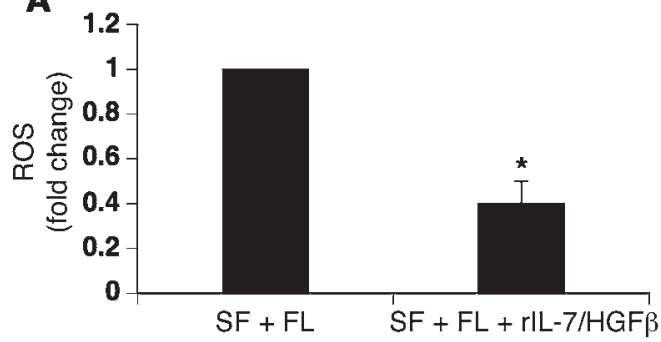

$$
\text { c }
$$

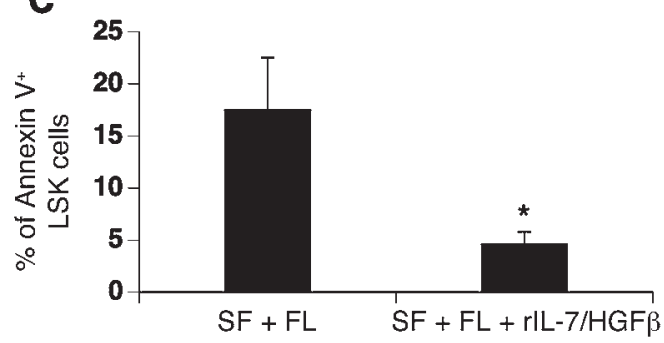

B

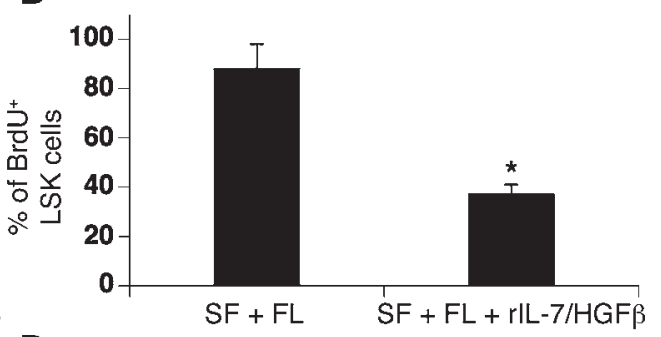

D

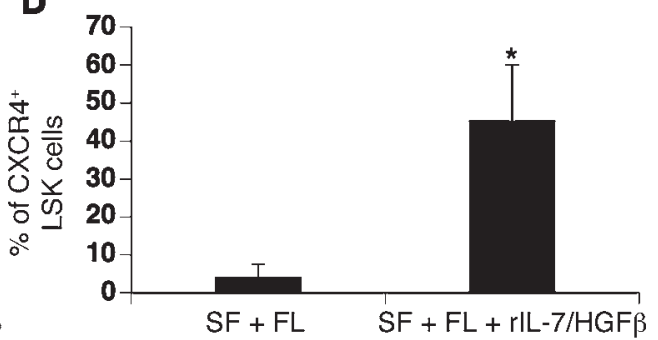

Figure 7

rIL-7/HGF $\beta$ decreases oxidative stress and proliferation of LSK cells generated in short-term cultures of SF/FL-stimulated BM cells and increases their survival and expression of CXCR4. BM was cultured for 7 days in SF/FL in the presence or absence of rIL-7/HGF $\beta$ as in Figure 6 , and the (A) relative amounts of ROS per LSK cell, (B) percentage of viable LSK cells that incorporated BrdU after a 45-minute pulse, (C) percentage of total LSK cells that were annexin V positive, and (D) percentage of viable LSK cells expressing CXCR4 were determined. Results represent mean \pm SD of data pooled from 3 independent experiments. ${ }^{*} P<0.05$ as compared with SF/FL only.

rHGF) was without effect when cells from the IL-7- and/or HGFcontaining ESC cocultures were infused i.v. (data not shown). Nonetheless, as shown in Figure 12, the cells from all of the ESC cocultures (including the PBS controls) were able to establish low levels of BM chimerism when they themselves were injected i.f., and the levels of chimerism could be increased significantly by the concurrent i.f. injection of rIL-7/HGF $\beta$. Even under these conditions, however, the i.f. injection of cells from the rIL-7/HGF $\beta$-containing ESC cocultures established significantly higher levels of hematopoietic chimerism than did equal numbers of cells from the rIL-7and/or HGF-containing cultures. However, even the donor-origin $\mathrm{BM}$ cells from the primary recipients of cells from the rIL-7/HGF $\beta$ containing ESC cocultures were unable to establish hematopoietic chimerism when injected i.v. into secondary recipients without i.f. injection of rIL-7/HGF $\beta$ (data not shown).

These results suggest that the i.f. injection of rIL-7/HGF $\beta$ enabled the ESC-derived HSCs from the rIL-7/HGF $\beta$-containing cocultures to migrate to and implant in the host $\mathrm{BM}$ but was unable to do so for their counterparts from the rIL-7- and/or rHGF-containing (or PBS-containing) cocultures. However, when the need for cell migration was bypassed, the i.f. injection of rIL-7/HGF $\beta$ was also able to enhance the ability of the ESC-derived HSCs from the latter cocultures to establish hematopoietic chimerism. Hence, the ESC-derived HSCs from the rIL-7- and/or rHGF-containing cocultures appeared to be less mature on average than were those from the rIL-7/HGF $\beta$ containing cocultures; and these in turn appeared to be less mature than were the HSCs from the rIL-7/HGF $\beta$-containing adult BM cell cultures, many of which could migrate to and implant in the BM in the absence of i.f.-injected rIL-7/HGF $\beta$ (Figure 2).

We then determined whether CD45-Lin-SSEA ${ }^{+} \mathrm{IL}-7 \mathrm{R} \alpha^{+} \mathrm{c}^{-\mathrm{Met}^{+}}$ HSC precursors were present in the ESC cultures. We found that 10- to 12-day-old murine ESC (TC-1/EGFP)/OP9 cell cocultures contained 2\%-3\% CD45- Lin $^{-} \mathrm{SSEA}^{+} \mathrm{IL}-7 \mathrm{R}^{+} \mathrm{c}-\mathrm{Met}^{+}$cells, which when purified and stimulated in vitro with rIL-7/HGF $\beta$, were able to reconstitute the hematopoietic system in vivo (Figure 13). These data suggest that, as in adult BM, CD45- ${ }^{-}$in $^{-} \mathrm{SSEA}^{+} \mathrm{IL}-7 \mathrm{R}^{+} \mathrm{c}-\mathrm{Met}^{+}$ HSC precursors in ESC cultures can be induced by rIL-7/HGF $\beta$ to develop into HSCs.

\section{Discussion}

In their aggregate, the present data indicate that rIL-7/HGF $\beta$ can induce the generation of at least 3 distinct subsets of HSCs in vitro, each of which can establish long-term multilineage hematopoietic
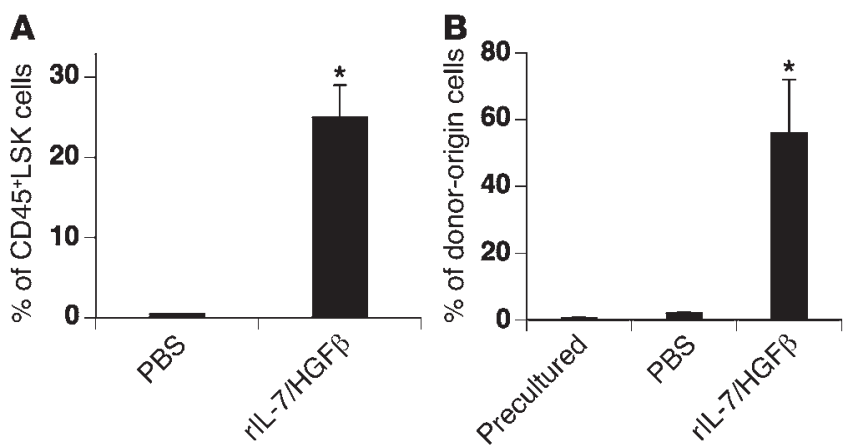

\section{Figure 8}

rIL-7/HGF $\beta$ induces the appearance of HSCs in short-term cultures of CD45-Lin-Sca-1+ cells. FACS-purified ( $\geq 98 \%$ ) CD45-Lin-Sca-1+ cells, freshly harvested from normal BM, were cultured for 12 days in the presence or absence of rIL-7/HGF $\beta$. (A) The percentages of culture-generated cells that were CD45+LSK cells and (B) donor-origin (GFP+) hematopoietic cells in the blood of lethally irradiated recipients 12 weeks after the i.v. transfer of $2 \times 10^{3}$ culture-generated and $2 \times 10^{5}$ Ly5.2 WT BM cells were determined. Mean \pm SD of groups of 5 mice. ${ }^{*} P<0.05$ versus PBS values. One representative experiment out of 2 is shown. 
A
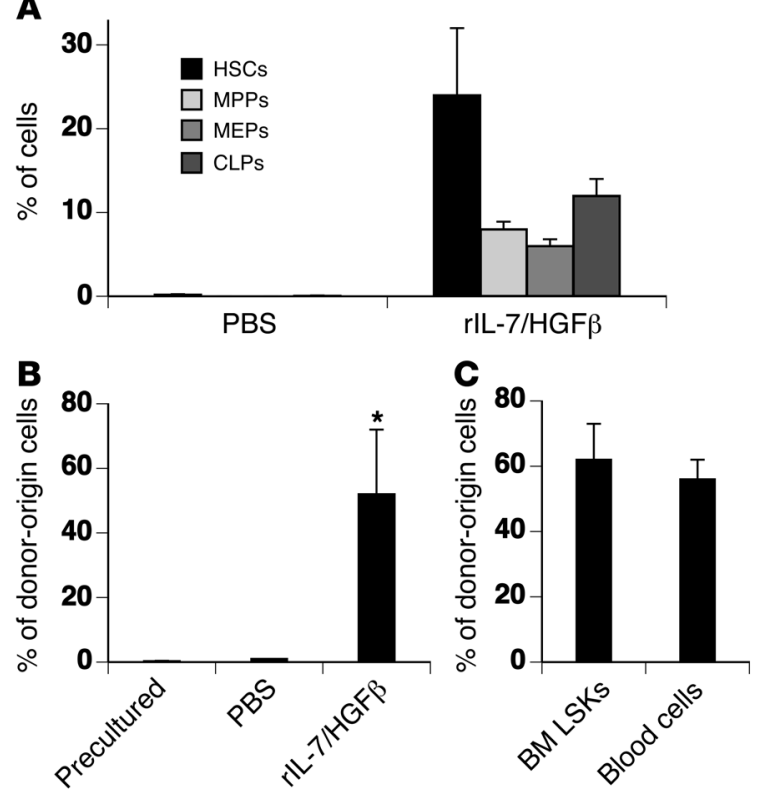

chimerism in vivo. These HSC subsets can be distinguished operationally by their respective abilities to migrate to and/or implant in the $\mathrm{BM}$ of irradiated recipients in the presence or absence of i.f.-injected rIL-7/HGFß. However, it is not known whether they represent different developmental stages of a single lineage or separate lineages that are produced at different stages of ontogeny (33).

The least mature subset of HSCs was generated by ESCs in OP-9 stromal cell cocultures that contained rIL-7 and/or rHGF (or PBS in lieu of cytokines). These HSCs did not migrate to the $\mathrm{BM}$ of irradiated recipients after i.v. injection, even when rIL-7/ HGF $\beta$ had been injected i.f. However, they were able to establish low levels of hematopoietic chimerism when they were injected directly into the BM, and, under these circumstances, i.f.-injected rIL-7/HGF $\beta$ further enhanced their ability to do so. A subset of HSCs of intermediate maturity was generated by ESCs in OP-9 stromal cell cocultures that contained rIL-7/HGF $\beta$. Although these cells did not migrate to the BM after i.v. injection, they could be induced to do so by the i.f. injection of rIL-7/HGF $\beta$. Thus, even in the presence of rIL-7/HGF $\beta$, ESCs did not generate definitive HSCs. The most mature subset of HSCs was generated by adult BM cells in cultures containing rIL-7/HGF $\beta$. These adult BM-derived HSCs spontaneously migrated to the BM and established long-term hematopoietic chimerism after i.v. injection. In addition, the level of chimerism could be significantly enhanced by the i.f. injection of rIL-7/HGF .

In addition to enhancing the migration of HSCs to the BM, it is possible that locally injected rIL-7/HGF $\beta$ directly or indirectly repairs the radiation-induced damage to the $\mathrm{BM}$ microenvironment (26-28). This is consistent with the known ability of HGF to enhance the migration and adhesion of HSCs to BM niches (32), to diminish oxidative stress-induced apoptosis (34), and to interact synergistically with a variety of hematopoietic cytokines (35-37). It also is consistent with the antiapoptotic properties of both HGF and IL-7 and with their abilities to enhance CXCR4 signaling and to upregulate and/or activate adhesion molecules on many cell types $(32,38,39)$. When combined with the unique signaling properties of rIL-7/HGF $\beta$ (see below), the results raise

\section{Figure 9}

rIL-7/HGF $\beta$ induces the appearance of HSCs in short-term cultures of CD45-Lin-SSEA+IL-7R $\alpha^{+}$C-Met ${ }^{+}$BM cells. FACS-purified ( $\geq 98 \%$ ) CD45-Lin-SSEA+IL-7R $\alpha^{+}$C-Met ${ }^{+}$BM cells freshly harvested from normal BM were cultured for 12 days in the presence or absence of rIL-7/ HGF $\beta$. (A) Percentages of HSCs (CD45+LSK Flt3-), MPPs (CD45+LSK Flt3 ${ }^{+}$), MEPs (CD45+ Lin-Sca-1-C-kit ${ }^{+}$Flt3 $\left.{ }^{+}\right)$, and CLPs (CD45+LSK Flt3+IL-7R $\alpha^{+}$) generated in vitro. (B) Donor-origin (Ly5.1) hematopoietic cells in the blood of lethally irradiated recipients (Ly5.2) 4 weeks after the i.v. transfer of $2 \times 10^{3}$ culture-generated and $2 \times 10^{5}$ Ly5.2 BM cells (or precultured cells and $2 \times 10^{5}$ Ly5.2 BM cells as controls). Neither feeder cells nor IL-7/HGF $\beta$ were included in the transplants. (C) $5 \times 10^{6} \mathrm{BM}$ cells from the primary recipients in $\mathbf{B}$ were mixed with $5 \times 10^{5}$ Ly5.2 BM cells and injected i.v. into lethally irradiated secondary recipients. The percentages of donor-origin LSK cells in the BM and hematopoietic cells in the blood were determined 4 weeks later. Mean \pm SD of groups of 4 to 5 mice. ${ }^{*} P<0.05$ versus control values. One representative experiment out of 2 is shown.

the additional possibility that rIL-7/HGF $\beta$ improves the BM microenvironment by increasing the local expression of molecules that regulate self-renewal, expansion, and/or fate determination of HSCs (40). One such defect may be related to the low levels of cytokine production in the irradiated BM, which adversely affect early B-lineage and T-lineage development and the mobilization of HSCs and MPPs (27-29, 41-43). Indeed, we have demonstrated here that i.f. injection of rIL-7/HGF $\beta$ significantly enhances thymocyte chimerism (Figure 4), and our recent demonstration that the systemic administration of rIL-7/HGF $\beta$ also rapidly restores thymocytopoiesis after HSC transplantation strongly supports such a mechanism (19).

Although our initial observations were made in long-term rIL-7/ HGF $\beta$-containing BM cell cultures, it was possible to greatly accelerate the generation of transplantable HSCs in these cultures

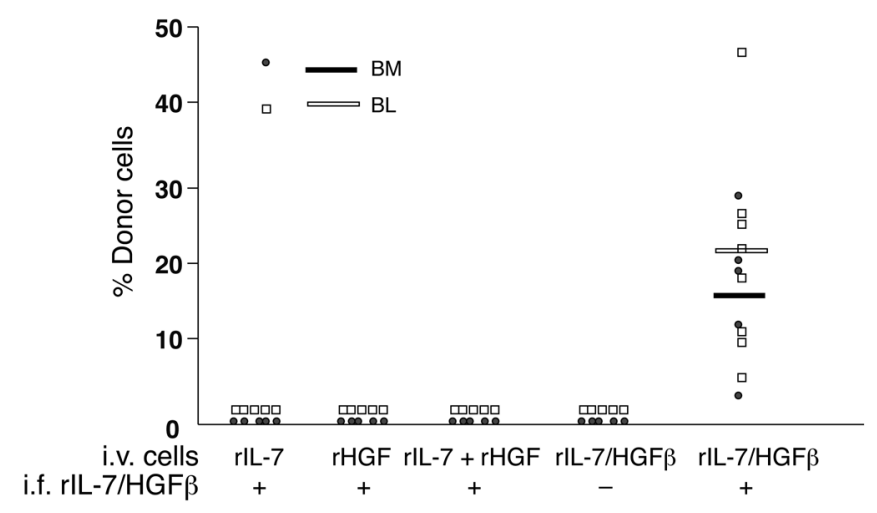

\section{Figure 10}

rIL-7/HGF $\beta$-stimulated ESC-derived cells require the i.f. injection of $\mathrm{rIL}-7 / \mathrm{HGF} \beta$ to engraft in BM and establish hemopoietic chimerism. $2 \times 10^{6}$ differentiated cells from cocultures of murine ESCs and OP9 stromal cells containing rIL-7/HGF $\beta$, rIL-7, and/or rHGF were injected i.v. into irradiated syngeneic 129SVEV Tac recipients that had also been injected i.f. with rlL-7/HGF $\beta$. The proportions of donor-origin (EGFP+) cells in the $B M$ and $B L$ of the recipients were determined 20 weeks later. One representative experiment out of 2 is shown. Each symbol denotes the percentage of donor cells in the BM (black square) or BL (white square) of an individual recipient mouse under the indicated experimental conditions. The horizontal bars indicate the mean values in the $\mathrm{BM}$ (black bar) or BL (white bar) of the respective groups of recipients. 


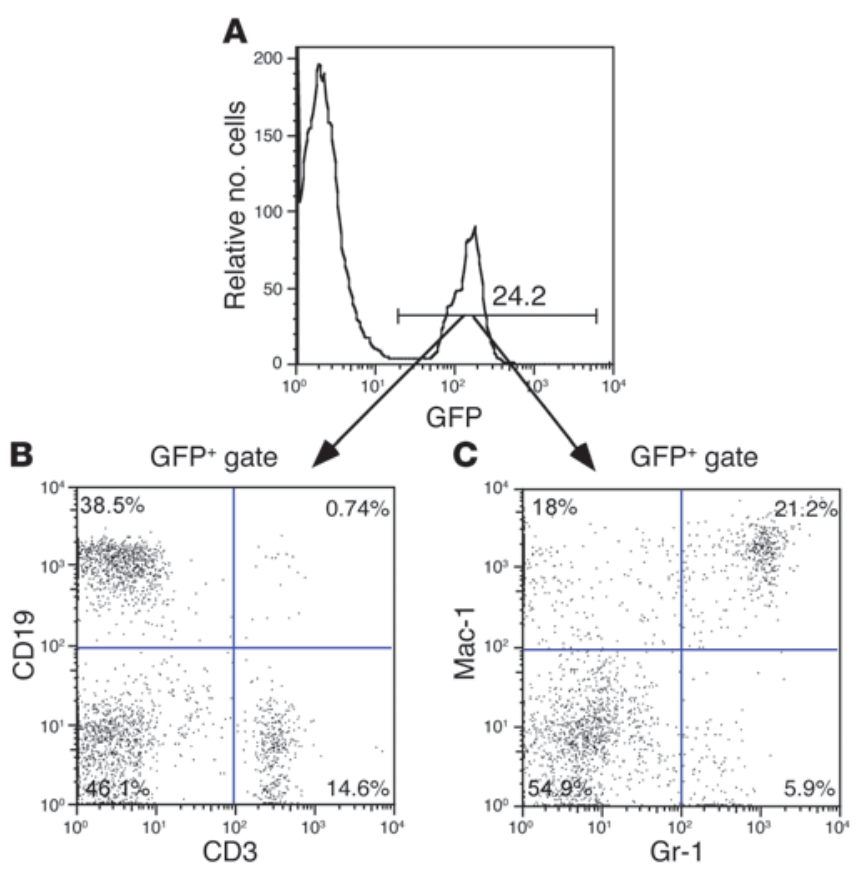

(7 days vs. 2 months) when SF/FL was added. As confirmed in cultures initiated with purified HSCs, the SF/FL appeared to stimulate the proliferation of preexisting HSCs, whereas rIL-7/HGF $\beta$ helped to maintain the viability and function of these SF/FL-stimulated HSCs. The rIL-7/HGF $\beta$ acted at least in part by preventing oxidative stress and preserving (or inducing) the quiescent $\left(\mathrm{G}_{0}\right)$ state of HSCs, possibly by enabling the proliferating HSCs in these cultures to reenter $\mathrm{G}_{0}$ phase and/or to upregulate genes implicated in HSC survival or migration $(30,31)$. However, as HSCs do not express the IL-7R $\alpha$ chain, it is difficult to explain the superior protective ability of rIL-7/HGF $\beta$, as compared with that of rHGF (or HGF $\beta$ ) alone. One possibility is that rIL-7/HGF $\beta$ coordinately binds to and signals through $\mathrm{c}$-Met and the $\gamma_{\mathrm{c}}$ chain. This is not implausible, as a functional hybrid receptor composed of the $\gamma \mathrm{c}$ chain and the $\beta$ chain of the GM-CSF receptor has been detected on human $\mathrm{CD} 34^{+}$hematopoietic cells (44). Another possibility is that the IL-7 component of rIL-7/HGF $\beta$ signals through other surface receptors, such as c-kit $(45,46)$. Whatever the mechanism, it is unlikely that rIL-7/HGF $\beta$ affects HSCs indirectly, as it is active in cultures of purified, SF/FL-stimulated HSCs.

In addition to preserving the hematopoietic reconstituting capacity of proliferating HSCs, it is possible that rIL-7/HGF $\beta$ further increases the size of the pool of transplantable HSCs in these short-term BM cell cultures by inducing the de novo formation of HSCs from CD45-Lin ${ }^{-}$precursors. This is supported by our demonstration that HSCs could be generated efficiently in short-term cultures of purified murine CD $45^{-} \mathrm{Lin}^{-} \mathrm{Sca}-1^{+}$or CD45- Lin $^{-}$SSEA ${ }^{+}$IL-7R $\alpha^{+} \mathrm{C}^{-\mathrm{Met}^{+}} \mathrm{BM}$ cells. Although it might be argued that the expanded populations of $\mathrm{CD} 45^{+} \mathrm{LSK}$ cells resulted from the selective outgrowth of a minor population of preexisting HSCs, this is unlikely as rIL-7/HGF $\beta$ does not stimulate the proliferation of HSCs and as SF/FL is not required in these cultures. Alternatively, it could be argued that the CD45- $\mathrm{Lin}^{-} \mathrm{Sca}-1^{+}$

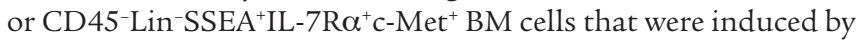
rIL-7/HGF $\beta$ to generate definitive HSCs were in fact embryonic or fetal-type HSCs that had not yet expressed hematopoietic-spe-

\section{Figure 11}

The donor-origin cells in the blood of the recipients of rL-7/HGF $\beta$-stimulated ESCs are composed of lymphoid and myeloid cells. (A) The percentages of donor-origin (GFP+) cells in the blood of irradiated mice were determined 20 weeks after the injection of cells from rIL-7/ HGF $\beta$-containing cocultures of murine ESCs (see Figure 10). (B) The presence of $\mathrm{T}$ cells $\left(\mathrm{CD}^{+}\right)$and $\mathrm{B}$ cells $\left(\mathrm{CD} 19^{+}\right)$and $(\mathbf{C})$ myeloid cells $\left(\mathrm{Gr}-1^{-} \mathrm{CD} 11 \mathrm{~b}^{+}\right)$and granulocytes $\left(\mathrm{Gr}-1^{+}\right)$among the donor-origin cells is shown. One representative experiment out of 2 is shown.

cific surface markers $(17,47)$. However, this is unlikely, as most embryonic and fetal-type HSCs express CD11b (48) and therefore would have been removed during the purification of the CD45Lin- BM cells (see Methods).

Because many CD45- $\mathrm{Lin}^{-} \mathrm{Sca}-1^{+} \mathrm{BM}$ cells express markers common to ESCs (e.g., Oct-4, CD71, SSEA-1, Nanog, Rex-1) and are reputed by some investigators to have the ability to generate tissues from all 3 germ layers, they originally were termed adult BM stem cells. However, this claim has been disputed, and it has been suggested instead that this primitive cell population has the appearance of pluripotency because it is composed of (or fuses with) a heterogenous mixture of tissue-committed stem cells $(24,25)$. Regardless, some CD45-Lin-Sca- $1^{+}$BM cells, including similar somatic precursor cell populations in human BM and umbilical cord blood, have been reported to have the ability to generate multilineage HSCs in vivo or in vitro, albeit inefficiently $(16,20-23,49-51)$. Importantly, we have demonstrated that purified CD45-Lin-SSEA+IL-7R $\alpha^{+}$c-Met ${ }^{+}$cells from BM and ESC cultures can generate HSCs in the presence of rIL-7/HGF $\beta$, suggesting these cells are HSC precursors. Based on our prior demonstration of the ability of rIL-7/HGF $\beta$ (as opposed to uncomplexed mixtures of IL-7 and HGF $\beta$ ) to physically cross-link and aggregate the receptors for HGF and IL-7 on the cell surface $(18,19,52)$, we predict that rIL-7/HGF $\beta$ can also cross-link the IL-7R $\alpha$ and c-Met receptors on these HSC precursors, resulting in juxtacrine interactions and the appearance of phosphorylated downstream products that differ from those observed when each receptor signals independently, even if simultaneously (ref. 53 and our

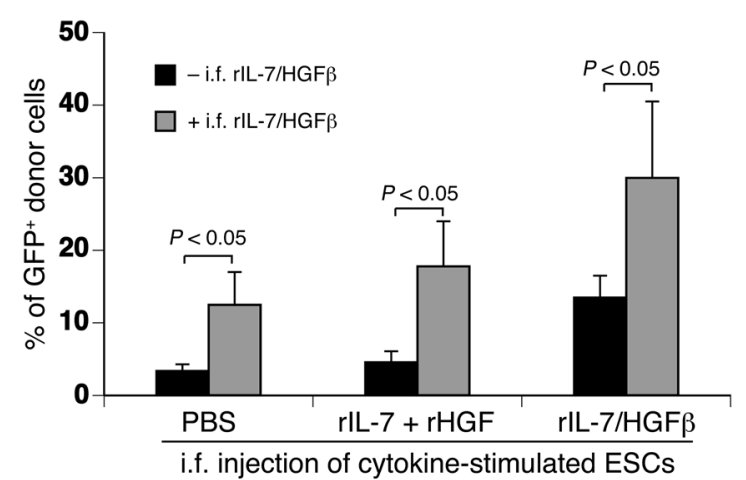

\section{Figure 12}

The i.f. injection of rlL-7/HGF $\beta$ enhances the engraftment of i.f.-injected ESC-derived HSCs. $5 \times 10^{5}$ cells from rlL-7/HGF $\beta$-, rlL-7 plus rHGF-, or PBS-containing ESC cocultures were mixed with rIL-7/HGF $\beta$ or PBS and injected i.f. into irradiated syngeneic recipients. Nine weeks later, the percentages of donor-origin (GFP+) cells in the BM of the recipients were determined. Mean \pm SD of 4 to 5 mice per group. One representative experiment out of 2 is shown. 


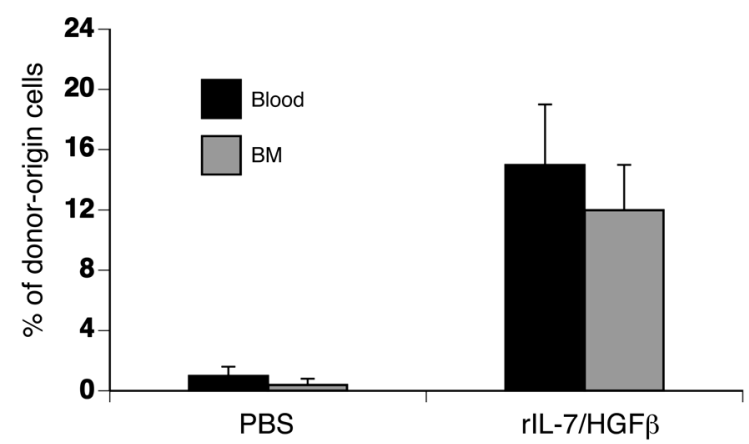

Figure 13

Purified CD45-Lin-SSEA+IL-7R $\alpha^{+}{ }^{+}-$Met $^{+}$HSC precursors from ESC cultures reconstitute the hematopoietic system in vivo after in vitro stimulation with rIL-7/HGF $\beta .2 \times 10^{4}$ CD45-Lin-SSEA ${ }^{+}$IL-7R $\alpha^{+} \mathrm{C}^{-\mathrm{Met}^{+}} \mathrm{HSC}^{\mathrm{H}}$ precursors that were purified from cocultures of murine ESCs and OP9 stromal cells were cultured with medium in the presence of PBS or rIL-7/HGF $\beta$ for 12 days. The cultured cells were then injected i.v. into irradiated 129SVEV Tac mice that had also been injected i.f. with rIL-7/HGF $\beta$. The proportions of donor-origin cells in the BM and blood of the recipients were determined 12 weeks later. Mean \pm SD of groups of 4 to 5 mice. One representative experiment out of 2 is shown.

unpublished observations). In support of this hypothesis, we have observed the appearance of such distinct products in rIL-7/HGF $\beta$ cross-linked CLPs (unpublished observations).

It remains to be determined whether any of the short-term HSC-producing culture systems described here holds promise for clinical application when appropriately modified. At present, the cultures of adult BM cells appear to have advantages over those of ESCs in that they generate definitive HSCs, do not require stromal cell layers, do not require (but may benefit from) the injection of cytokine into the BM cavity, and do not run the risk of inducing teratomas. Although cultures using unseparated BM cells are the simplest to establish, cultures using purified HSCs or CD45- $\mathrm{Lin}^{-}$ Sca- $1^{+}$or $\mathrm{CD} 45^{-} \mathrm{Lin}^{-} \mathrm{SSEA}{ }^{+} \mathrm{IL}-7 \mathrm{R}^{+} \mathrm{c}^{-\mathrm{Met}^{+}} \mathrm{BM}$ cells have the advantage of producing high proportions of $\mathrm{CD} 45^{+} \mathrm{LSK}$ cells, thereby enabling HSCs to be easily purified prior to transplantation. In addition, untreated cultures of self-replicating CD45- Lin $^{-} \mathrm{Sca}-1^{+}$ or $\mathrm{CD}^{4} 5^{-} \mathrm{Lin}^{-} \mathrm{SSEA}^{+} \mathrm{IL}-7 \mathrm{R}^{+} \mathrm{C}-\mathrm{Met}^{+} \mathrm{BM}$ cells have the potential to serve as reservoirs for the continuous or intermittent induction of HSCs by rIL-7/HGF $\beta$ and might also prove useful in HSC gene transfer therapy (54). Also, the production of HSCs in these cultures could be further amplified by the addition of SF/FL or other early-acting cytokines. Hence, by (a) stimulating the efficient in vitro production of transplantable HSCs from earlier precursors; (b) protecting proliferating HSCs against the loss of in vivo repopulating ability; (c) supporting the migration and engraftment of HSCs to/in the BM; and (d) enhancing thymocytopoiesis and naive $\mathrm{T}$ cell regeneration in irradiated recipients (unpublished observations), rIL-7/HGF $\beta$ has the potential to overcome several of the major obstacles to the widespread employment of HSC transplantation as a therapeutic modality.

\section{Methods}

Animals. Ly 5 congenic C57BL/6NCR (B6) mice were obtained from the National Cancer Institute. EGFP transgenic mice that were backcrossed to the $\mathrm{C} 57 \mathrm{BL} / 6$ genetic background were provided by Troy Randall (Trudeau Institute, Saranac Lake, New York, USA). The EGFP expression in these mice is controlled by the chicken actin promoter and CMV enhancer. Breeding pairs of $I L-7 R \alpha^{-/-}$mice (B6.129S7 mice) were purchased from The Jackson Laboratory.

Antibodies. FITC-, PE-, APC-, APC-Cy7-, or biotin-conjugated (or unconjugated) antibodies against mouse CD19, TER119, CD45, CD3, CD4, and CD8 (BioLegend); Ly 5.1, Ly 5.2, c-kit, Sca-1, Flt3, B220, Gr-1, CD11b, SSEA, CXCR4, and Ki-67 (BD Biosciences); and IL-7R $\alpha$ chain (CD127) and c-Met (eBiosciences) were used. The BrdU Flow Kit was obtained from BD Biosciences, and anti-Biotin, APC, and PE MicroBeads were obtained from Miltenyi Biotec.

The expression of cell surface antigens (and GFP, annexin V, and propidium iodide) was determined by multicolor analysis on either a FACSCalibur or LSR II flow cytometer (BD Biosciences). Lineage-negative (Lin-) cells were detected using a mixture of antibodies to CD3, Gr-1, CD11b, TER-119, and B220. In adoptive transfer experiments, EGFP and/or Ly5.1 and Ly5.2 alleles were used to identify donor- and host-origin cells, Data were analyzed using Flowjo software (Tree Star Inc.). Background fluorescence for multicolor analysis was determined using mixtures of all of the conjugated antibodies minus the relevant antibody.

FACS and immunomagnetic cell separation. HSCs (CD45 ${ }^{+}$Flt3-LSK cells) and $\mathrm{CD}^{-} 5^{-} \mathrm{Lin}^{-} \mathrm{Sca}-1^{+} \mathrm{BM}$ cells were purified from normal mouse BM by combined immunomagnetic cell separation and FACS. The cells were stained with anti-CD45, developed with secondary antibody-conjugated MicroBeads (Miltenyi Biotec), and applied to an LD column to separate the $\mathrm{CD} 45^{+}$and $\mathrm{CD} 45^{-}$cell populations. The separated cells were stained with lineage and other markers, and the HSCs and CD45- Lin-Sca- $^{-}{ }^{+}$or CD45-Lin-SSEA+IL-7R $\alpha^{+} \mathrm{c}-\mathrm{Met}^{+} \mathrm{BM}$ cells were further purified (>98\%) by FACS sorting for use in cell culture or adoptive transfer experiments.

Murine ESCs. ESC line TC-1 (obtained from our Gene Targeting and Transgenic Facility) was derived from a 129SVEVTac blastocyst. The ESCs were maintained in an undifferentiated state by culture on embryonic fibroblasts (MEFs) and LIF and then adapted to serum-free and MEF-independent culture conditions by using ESGRO Complete serum-free clonal grade medium (Chemicon International Inc.). The ESCs were transfected by electroporation with pEGFP-N1 expression vector (Clonotech), selected in ESGRO medium containing G418 in 96-well plates, and expanded to twenty-four 6-well plates after the cells grew to confluence. Although some of the clones lost expression of EGFP after several passages, we were able to select one clone that stably expressed EGFP for at least 24 passages following transfection. Like the WT ESCs, EGFP-ESCs expressed alkaline phosphatase, suggesting that they were in an undifferentiated state.

$B M$ cell culture. BM was collected from the femurs and tibias of 4- to 6-week-old EGFP transgenic (C57BL/6 genetic background) or (129 X B6) $\mathrm{F}_{2}$ mice and cultured $\left(10^{6} \mathrm{BM}\right.$ cells/well) in 6-well plates in RPMI- 1640 plus $5 \%$ lot selected, defined FBS containing $5 \times 10^{-5} \mathrm{M} 2-\mathrm{ME}$, as described previously (18). rIL-7/HGF $\beta$ (30 ng/ml), rIL-7 (10 ng/ml), and/or rHGF $(25 \mathrm{ng} / \mathrm{ml})$ were added to the cultures as indicated (see Results). rIL-7 and HGF were purchased from R\&D Systems. The single-chain rIL-7/HGF $\beta$ was expressed and purified as described previously (18). However, as the same results were obtained with $\mathrm{rHGF}$ as with $\mathrm{rHGF} \beta$, only the results using rHGF are shown. The cultures were refed with $50 \%$ fresh medium and cytokines twice weekly. For long-term cultures, total cells (nonadherent plus adherent) were harvested at 1 and 2 months and stained with fluorescent antibodies for phenotypic analysis. Short-term cultures (7-14 days) were set up in some experiments using whole BM, purified

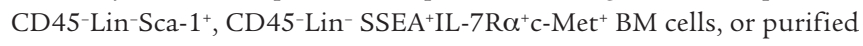
CD $45^{+}$LSK Flt3- HSCs. In the ESC cultures, undifferentiated TC-1/EGFP ESCs were cocultured with OP9 cells, as described previously (55), and equimolar amounts of rIL-7/HGF (30 ng/ml), rIL-7 $(10 \mathrm{mg} / \mathrm{ml})$, and/or $\mathrm{rHGF} \beta(20 \mathrm{mg} / \mathrm{ml})$ were added to the cultures initially and whenever the 
medium was changed. In the whole BM cell cultures, $\mathrm{rSCF}(50 \mathrm{ng} / \mathrm{ml})$ plus rFlt $3 \mathrm{~L}(50 \mathrm{ng} / \mathrm{ml})$ was added to the medium alone or in combination with the above cytokines.

Competitive in vivo transplantation assays. Cultured BM cells were mixed in indicated numbers (see Results) with $2 \times 10^{5}$ freshly harvested host-type BM cells and injected via tail vein into irradiated (10 Gy) recipients. Some of the mice were also injected i.f. with rIL-7/HGF $\beta$ (500 ng once per month), as described previously (56). Blood samples and tissues were collected at the indicated times (see Results), and donor-origin cells were quantified and analyzed for the expression of lineage markers. To assess radioprotection, cultured BM cells were injected i.v. into lethally irradiated (10 Gy) mice without competitor BM cells. A radioprotection end point of 6 weeks was used.

BrdU incorporation. $10 \mu \mathrm{l}$ of $1 \mathrm{mM} \mathrm{BrdU}$ solution (BD Biosciences) was added per $\mathrm{ml}$ of cultured $\mathrm{BM}$ cells. The treated cells were incubated at $37^{\circ} \mathrm{C}$ for 45 minutes and stained with conjugated antibodies for cell-surface markers. After fixation and treatment with DNase, the permeabilized cells were stained with APC-labeled anti-BrdU antibody and analyzed by flow immunocytometry.

Analysis of intracellular ROS. Cytokine-cultured BM cells were loaded with $5 \mu \mathrm{M} 2^{\prime}$ - $7^{\prime}$-dichlorofluorescein diacetate (DCF-DA) (Sigma-Aldrich) and incubated on a shaker at $37^{\circ} \mathrm{C}$ for 30 minutes. The cells were then stained with antibodies for LSK and analyzed by flow cytometry. The peak excitation wavelength for oxidized DCF was $488 \mathrm{~nm}$, and that for emission was $525 \mathrm{~nm}$.
Statistics. $P$ values were based on 2-tailed Student's $t$ test. A confidence level above $95 \%(P<0.05)$ was determined as significant.

Study approval. All mice were housed under specific pathogen-free conditions in the Center for Laboratory Animal Care, University of Connecticut Health Center and University of Connecticut, and were used according to protocols approved by the Institutional Animal Care and Use Committee of University of Connecticut and University of Connecticut Health Center.

\section{Acknowledgments}

This study was supported in part by NIH grant AI32752 and a grant from the Connecticut Stem Cell Research Program (10SCB12).

Received for publication April 26, 2012, and accepted in revised form July 26, 2012.

Address correspondence to: Irving Goldschneider, Department of Immunology, School of Medicine, University of Connecticut Health Center, 263 Farmington Ave., Farmington, Connecticut 06030, USA. Phone: 860.679.4244; Fax: 860.679.2936; E-mail: igoldsch@neuron.uchc.edu. Or to: Laijun Lai, Department of Allied Health Sciences, University of Connecticut, 1390 Storrs Road, Storrs, Connecticut 06269, USA. Phone: 860.679.6073; Fax: 860.486.6073; E-mail: laijun.lai@uconn.edu.
1. Sorrentino BP. Clinical strategies for expansion of haematopoietic stem cells. Nat Rev Immunol. 2004; 4(11):878-888.

2. Ross J, Li L. Recent advances in understanding extrinsic control of hematopoietic stem cell fate. Curr Opin Hematol. 2006;13(4):237-242.

3. Devine SM, Lazarus HM, Emerson SG. Clinical application of hematopoietic progenitor cell expansion: current status and future prospects. Bone Marrow Transplant. 2003;31(4):241-252.

4. McNiece I. Ex vivo expansion of hematopoietic cells. Exp Hematol. 2004;32(5):409-410.

5. Amsellem S, et al. Ex vivo expansion of human hematopoietic stem cells by direct delivery of the HOXB4 homeoprotein. Nat Med. 2003; 9(11):1423-1427.

6. Reya $\mathrm{T}$, et al. A role for Wnt signalling in self-renewal of haematopoietic stem cells. Nature. 2003;423(6938):409-414.

7. Stier S, Cheng T, Dombkowski D, Carlesso N, Scadden DT. Notch1 activation increases hematopoietic stem cell self-renewal in vivo and favors lymphoid over myeloid lineage outcome. Blood. 2002; 99(7):2369-2378

8. Von Drygalski A, Alespeiti G, Ren L, Adamson JW. Murine bone marrow cells cultured ex vivo in the presence of multiple cytokine combinations lose radioprotective and long-term engraftment potential. Stem Cells Dev. 2004;13(1):101-111.

9. Glimm H, Oh IH, Eaves CJ. Human hematopoietic stem cells stimulated to proliferate in vitro lose engraftment potential during their $\mathrm{S} / \mathrm{G}(2) / \mathrm{M}$ transit and do not reenter $\mathrm{G}(0)$. Blood. 2000; 96(13):4185-4193.

10. Summers YJ, Heyworth CM, de Wynter EA, Chang J, Testa NG. Cord blood G(0) CD34+ cells have a thousand-fold higher capacity for generating progenitors in vitro than G(1) CD34+ cells. Stem Cells. 2001;19(6):505-513.

11. Ito $\mathrm{K}$, et al. Reactive oxygen species act through $\mathrm{p} 38$ MAPK to limit the lifespan of hematopoietic stem cells. Nat Med. 2006;12(4):446-451.

12. Yeoh JS, et al. Fibroblast growth factor- 1 and -2 preserve long-term repopulating ability of hematopoietic stem cells in serum-free cultures. Stem Cells. 2006;24(6):1564-1572.
13. Arai F, et al. Tie2/angiopoietin-1 signaling regulates hematopoietic stem cell quiescence in the bone marrow niche. Cell. 2004;118(2):149-161.

14. Glimm H, Tang P, Clark-Lewis I, von Kalle C, Eaves C. Ex vivo treatment of proliferating human cord blood stem cells with stroma-derived factor-1 enhances their ability to engraft NOD/SCID mice. Blood. 2002;99(9):3454-3457.

15. Wiesmann A, et al. Modulation of hematopoietic stem/progenitor cell engraftment by transforming growth factor beta. Exp Hematol. 2000;28(2):128-139.

16. Weinreich MA, et al. Growth factor receptors as regulators of hematopoiesis. Blood. 2006; 108(12):3713-3721

17. Tian X, Kaufman D. Differentiation of embryonic stem cells towards hematopoietic cells: progress and pitfalls. Curr Opin Hematol. 2008;15(4):312-318.

18. Lai L, Zeff RA, Goldschneider I. A recombinant single-chain IL-7/HGF $\beta$ hybrid cytokine induces juxtacrine interactions of the IL-7 and HGF (c-Met) receptors and stimulates the proliferation of CFU-S12, CLPs, and pre-pro-B cells. Blood. 2006; 107(5):1776-1784.

19. Jin J, Goldschneider I, Lai L. In vivo administration of the rIL-7/HGF $\beta$ hybrid cytokine restores thymopoiesis and naïve $T$ cell generation in lethally-irradiated mice after syngeneic bone marrow transplantation. J Immunol. 2011;186(4):1915-1922.

20. Kucia M, et al. A population of very small embryonic-like (VSEL) CXCR4(+)SSEA-1(+)Oct-4+ stem cells identified in adult bone marrow. Lenkemia. 2006; 20(5):857-869.

21. Serafini M, et al. Hematopoietic reconstitution by multipotent adult progenitor cells: precursors to long-term hematopoietic stem cells. J Exp Med. 2007; 204(1):129-139.

22. Ratajczak MZ, Zuba-Surma EK, Wysoczynski M, Ratajczak J, Kucia M. Very small embryonic-like stem cells: characterization, developmental origin, and biological significance. Exp Hematol. 2008; 36(6):742-751

23. Jiang $Y$, et al. Pluripotency of mesenchymal stem cells derived from adult marrow. Nature. 2002; 418(6893):41-49.

24. Reyes M, Li S, Foraker J, Kimura E, Chamberlain JS. Donor origin of multipotent adult pro- genitor cells in radiation chimeras. Blood. 2005; 106(10):3646-3649.

25. Wagers AJ, Weissman IL. Plasticity of adult stem cells. Cell. 2004;116(5):639-648.

26. Goodell MA. Stem-cell "plasticity": befuddled by the muddle. Curr Opin Hematol. 2003;10(3):208-213.

27. Chung B, Barbara-Burnham L, Barsky L, Weinberg K. Radiosensitivity of thymic interleukin-7 production and thymopoiesis after bone marrow transplantation. Blood. 2001;98(5):1601-1606.

28. Mazo IB, Quackenbush EJ, Lowe JB, von Andrian UH. Total body irradiation causes profound changes in endothelial traffic molecules for hematopoietic progenitor cell recruitment to bone marrow. Blood. 2002;99(11):4182-4191.

29. Testa NG, Hendry JH, Molineux G. Long-term bone marrow damage in experimental systems and in patients after radiation and chemotherapy. Anticancer Res. 1985;5(1):101-110.

30. Miller CL, Eaves CJ. Expansion in vitro of adult murine hematopoietic stem cells with transplantable lympho-myeloid reconstituting ability. Proc Natl Acad Sci U S A. 1997;94(25):13648-13653.

31. Araki H, Yoshinaga K, Boccuni P, Zhao Y, Hoffman R, Mahmud N. Chromatin-modifying agents permit human hematopoietic stem cells to undergo multiple cell divisions while retaining their repopulating potential. Blood. 2007;109(8):3570-3578.

32. Son BR, et al. Migration of bone marrow and cord blood mesenchymal stem cells in vitro is regulated by stromal-derived factor-1-CXCR4 and hepatocyte growth factor-c-met axes and involves matrix metalloproteinases. Stem Cells. 2006;24(5):1254-1265.

33. Ratajcak MZ, Machalinski B, Wojakowski W, Ratajczak J, Kucia M. A hypothesis for an embryonic origin of pluripotent Oct-4+ stem cells in adult bone marrow and other tissues. Leukemia. 2007; 21(5):860-867.

34. Kannan R, Jin M, Gamulescu MA, Hinton DR. Ceramide-induced apoptosis: role of catalase and hepatocyte growth factor. Free Radic Biol Med. 2004; 37(2):166-175.

35. Yu SZ, et al. Stimulatory effects of hepatocyte growth factor on hemopoiesis of CSF/c-kit system-deficient mice. Stem Cells. 1998;16(1):66-77.

36. Galimi F, et al. Hepatocyte growth factor induces 
proliferation and differentiation of multipotent and erythroid hemopoietic progenitors. J Cell Biol. 1994;127(6 pt 1):1743-1754.

37. Kmiecik TE, Keller JR, Rosen E, Vande Woude GF. Hepatocyte growth factor is a synergistic factor for the growth of hematopoietic progenitor cells. Blood. 1992;80(10):2454-2457.

38. Aiello FB, et al. IL-7 Induces myelopoiesis and erythropoiesis. J Immunol. 2007;178(3):1553-1563.

39. Schmitt N, et al. Positive regulation of CXCR4 expression and signaling by interleukin-7 in CD4+ mature thymocytes correlates with their capacity to favor human immunodeficiency $\mathrm{X} 4$ virus replication. J Virol. 2003;77(10):5784-5793.

40. Zhang J, et al. Identification of the haematopoietic stem cell niche and control of the niche size. Nature. 2003;425(6960):836-841.

41. Foss DL, Donskoy E, Goldschneider I. The importation of hematogenous precursors by the thymus is a gated phenomenon in normal adult mice. J Exp Med. 2001;193(3):365-374.

42. Donskoy E, Foss DL, Goldschneider I. Gated importation of prothymocytes by adult mouse thymus is coordinated with their periodic mobilization from bone marrow. J Immunol. 2003;171(7):3568-3575.

43. Porter DL, June CH. T-cell reconstitution and expansion after hematopoietic stem cell transplantation: 'T' it up! Bone Marrow Transplant. 2005; 35(10):935-942.

44. Giron-Michel J, et al. Detection of a functional hybrid receptor gammac/GM-CSFRbeta in human hematopoietic CD34+ cells. J Exp Med. 2003; 197(6):763-775.

45. Fry TJ, Mackall CL. Interleukin-7: from bench to clinic. Blood. 2002;99(11):3892-3904.

46. Cosenza L, Gorgun G, Urbano A, Foss F. Interleukin-7 receptor expression and activation in nonhaematopoietic neoplastic cell lines. Cell Signal. 2002; 14(4):317-325.

47. McKinney-Freeman SL, et al. Surface antigen phenotypes of hematopoietic stem cells from embryos and murine embryonic stem cells. Blood. 2009;114(2):268-278.

48. Kim I, He S, Yilmaz OH, Kiel MJ, Morrison SJ. Enhanced purification of liver hematopoietic stem cells using SLAM family receptors. Blood. 2006; 108(2):737-744.

49. D'Ippolito G, et al. Marrow-isolated adult multilineage inducible (MIAMI) cells, a unique population of postnatal young and old human cells with extensive expansion and differentiation potential. J Cell Sci. 2004;117(pt 14):2971-2981.
50. Yoon YS, et al. Clonally expanded novel multipotent stem cells from human bone marrow regenerate myocardium after myocardial infarction. J Clin Invest. 2005;115(2):326-338.

51. Kogler G, et al. A new human somatic stem cell from placental cord blood with intrinsic pluripotent differentiation potential. J Exp Med. 2004; 200(2):123-135

52. Wei C, Lai L, Goldschneider I. Pre-pro-B cell growth-stimulating factor (PPBSF) upregulates IL-7R $\alpha$ chain exppession and enables pro-B cells to respond to monomeric IL-7. J Interferon Cytokine Res. 2002;22(7):823-832.

53. Mellado $\mathrm{M}$, et al. Chemokine receptor homo-or heterodimerization activates distant signaling pathways. EMBO J. 2001;20(10):2497-2507.

54. Van Damme A, Driessche TV, Collen D, Chuah MKL. Bone marrow stromal cells as targets for gene therapy. Curr Gene Ther. 2002;2:195-209.

55. Nakano T, Kodama H, Honjo T. Generation of lymphohematopoietic cells from embryonic stem cells in culture. Science. 1994;265(5175):1098-1101.

56. Yahata T, et al. A highly sensitive strategy for SCID-repopulating cell assay by direct injection of primitive human hematopoietic cells into NOD/SCID mice bone marrow. Blood. 2003;101(8):2905-2913. 